\title{
The Influence of Cinema Screen Colors on The Heart Rate and Blood Pressure among Students in the College of Fine Arts

\author{
Rajaa Hameed Rasheed (MSc) ${ }^{1}$
} \\ Abstract
}

Background: The strong relationship between hypertension and stress have been confirmed in previous studies. The stress has been shown in rise blood pressure by rising heart rate and the cardiac output .

Objective: To test the influences of exposure to red versus green light colors of cinema screen on the rate of heart beat and blood pressure among healthy college students.

Patients and Methods: In this study a twenty eight apparently healthy students from college of fine arts Diyala University were enrolled. They were 18 males and 10 females with a mean age 22 years. Verbal consent was obtained from all participants. They were exposed to two colored lights of cinema screen (red and green) viewing at a distance 4 meters. The watching time was continued for 15 minutes. Thereafter ten minutes the systolic blood pressure [SBP], diastolic blood pressure [DBP] and heart rate was measured by medical personals. Data were collected and statistical analysis was done using the SPSS version 20 and P value was counted significant whenever it is less than 0.05 .

Results: The results revealed that the exposure to red light increases both systolic and diastolic blood pressure and heart rate compared to the green light, since the mean \pm SD of diastolic blood pressure for red light and green light are 8.22 \pm 0.59 and 8.02 \pm 0.66 versus that of the control is $7.81 \pm 0.46 \mathrm{cmHg}$. Thus Red and green light had a significant effect on diastolic blood pressure $(\mathrm{P}<0.05)$. Whereas, the mean $\pm \mathrm{SD}$ of systolic blood pressure for red light and green light are $11.85 \pm 1.11$ and $11.77 \pm 1.24$ versus that of the control $(11.75 \pm 0.96) \mathrm{cmHg}$, with insignificant difference $(\mathrm{P}>0.05)$. The mean $\pm \mathrm{SD}$ of heart rate for red light and green light are $79.75 \pm 11.19$ and $79.10 \pm 9.87$ versus that of the control $76.71 \pm 8.81$ beats $/ \mathrm{min}$.

Conclusion: Exposure to red and green cinema screen colors is altering autonomic nervous functions as expressed by increasing the blood pressure and heart rate among healthy college students.

Keywords: Stress, Cinema screen, Diastolic blood pressure, Heart beats

Corresponding Author: rajaa.hameed1965@gmail.com

Received: $14^{\text {th }}$ January 2020

Accepted: $5^{\text {th }}$ February 2020

DOI:https://doi.org/10.26505/DJM.18025170114

\footnotetext{
${ }^{1}$ Collage of Fine Arts-Diyala University- Diyala -Iraq.
} 


\section{Introduction}

The light wavelengths between (400-700) $\mathrm{nm}$ are used for visible environment and color by the rod and cone cell that responds in different wavelength of visible light, it has direct effect on the biosignal and emotion [1]. Colors are important for our sensations and recognition [2, 3]. Red and blue color has effect on brain and cardiovascular activities [4].

Physiological effects of color on person have been a lot of attention. Concerning the sentimental effect of the thing color, the red color excites pleasant positive and called the warm colors, active sensations, clam, ordinary sensations, but the blue color produces cold, inactive, quite sensations[5]. The previous studies had supplied support for the advantageous influences of light, showing a positive effect on animation, depressive signs [6].It has been showed that the color of light can effect heart rate variability rapidly and that the effects of the colors can be discrete by heart rate variability test[7]. Heart rate variability $\mathrm{HRV}$ has been a medical device for examination of disorganizes of the cardiovascular in the past years [8]. Different heart rate variability parameters have been found to be affected differently on different colored light exposures. Red has shown to have an impact, mainly on the sympathetic system [9].

Studies analyzed HRV provides that two opposing parts of the autonomous nervous system (sympathetic \& parasympathetic) nervous system are regulating the HRV [10, 11]. Red room regulates the tension and stimulates to increase the pulse rate [4]. Thus exposure to red color causes to increase the blood pressure and heart to beat faster [12]. The effects of color on stress perception with regards to white, red and green environments. It has been found that topics in the red case had higher tension order signs compared to the green or white case [13]. Significant effects of different colors on blood pressure had been reported. Red color increases blood pressure while green color has fluctuating effects [14].

Residential surrounding greenness and living closer to natural environments contribute to better physical functioning at older ages [15]. Increasing physical activity, reducing psychological stress, anxiety and depression have been suggested as possible mechanisms underlying health benefits of green spaces. Prolonged exposure to red screen causes a stress, stress may has effect on cardiovascular system [16].

\section{Patients and Methods}

Approval was obtained from the students before the start of the study due to the ethical guidelines, the using instrument should not be unhealthy to the student. Therefore, verbal consent was obtained from all participants before enrollment.

Twenty eight apparently healthy students from College of Fine Arts- Diyala University were included. They were 18 males and 10 females with mean age 22 years. The study was conducted from $1^{\text {st }}$ December 2018 to February $1^{\text {st }}$ 2019. Two colored lights of screen were used in this study (red \& green) viewing at a distance 4 meters. Automatic Digital Blood Pressure Monitor was used to 
measure the blood pressure and heart rate. The study procedures include:

1-Record blood pressure (systolic and, diastolic), and heart rate before watching the display (control).

2-The students were exposed to red light emitted from cinema screen for 15 minutes.

3 -Resting period of 10 minutes.

4-Record systolic blood pressure (SBP), diastolic blood pressure (DBP), and heart.

5-Repeats procedures $(2,3$, and 4) for green light emitted from cinema screen rate.

Table (1) :Mean systolic and diastolic blood pressure for study groups after exposed to red and green

light of cinema screen

\begin{tabular}{||c||c||c|c|}
\hline \multirow{2}{*}{ Outcome } & \multicolumn{3}{|c|}{ Groups } \\
\cline { 2 - 4 } & Control & Red & Green \\
\hline \hline $\mathrm{DBP} / \mathrm{cmHg}$ & $7.81 \pm 0.46$ & $8.22 \pm 0.59$ & $8.02 \pm 0.66$ \\
\hline \hline SBP/cmHg & $11.75 \pm 0.96$ & $11.85 \pm 1.11$ & $11.77 \pm 1.24$ \\
\hline \hline HR/(beats/min) & $76.71 \pm 8.81$ & $79.75 \pm 11.19$ & $79.10 \pm 9.87$ \\
\hline
\end{tabular}

To investigate the effects of color light for cinema screen on blood pressure and Heart rate, analysis was used which revealed that light's color does affect the blood pressure. An increase in heart rate was observed when the students are exposed to red and green light as shown in Figure (1). It was appeared

\section{Statistical analysis}

All data entered using statistical PC software; (SPSS).

\section{Results}

The mean systolic blood pressure (SBP) for red light viewing compared the control, there were increasing percentage about $0.91 \%$, while green light viewing about $0.21 \%$. Mean diastolic blood pressure (DBP) for red and green light viewing respectively were increasing about $5.21 \%, 2.7 \%$. that the diastolic blood pressure for control, after exposed to red and green light of cinema screen, the diastolic blood pressure ( DBP) value significantly increases when the students are exposed to red light and green light, but increases DBP values of green light are lower than red color.

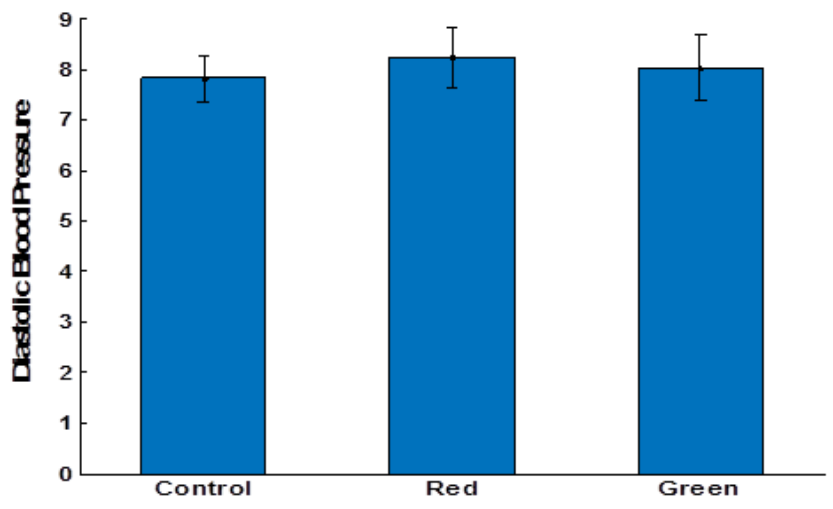

Figure (1): Effects of color light on DBP 
Figure (2) showed the systolic blood pressure for control, after exposed to red and green light of cinema screen, the systolic blood pressure (SBP) values are nonsignificantly increasing after exposure to red color and green color.

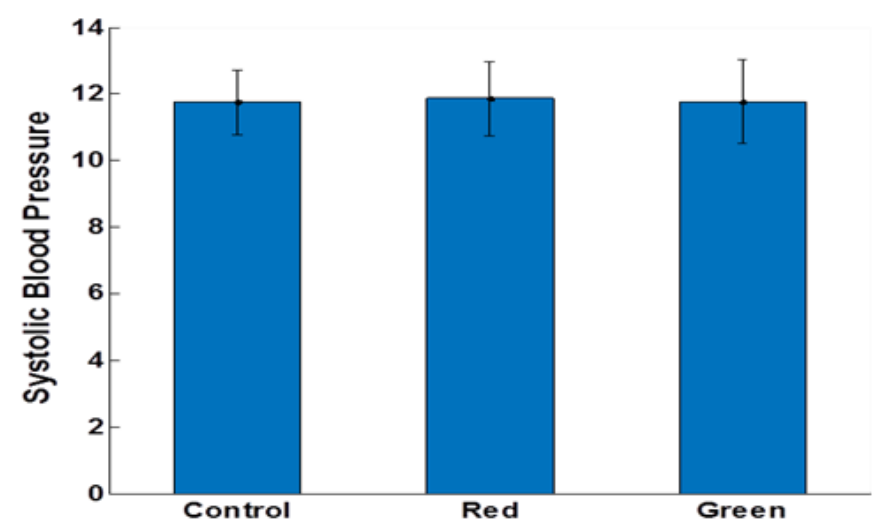

Figure (2): Effect of color light on SBP

Figure (3) shows the heart rates for control, and green light color. Mean Heart rate is after exposure to red color and green color, significantly increases after exposure to red the Mean Heart rate values for 28 students and green color but for red light the case is when exposed in colored illumination of red more affective.

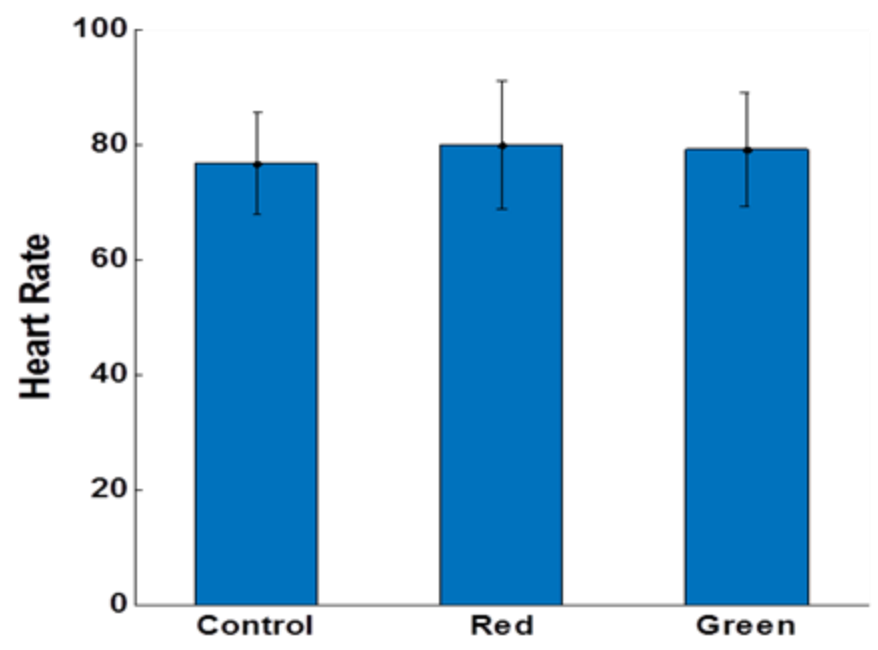

Figure (3): Effect of color light on heart rate 
The Influence of Cinema Screen Colors on The Heart Rate and Blood Pressure among Students in the

Table (2): Mean variation of DBP, SBP and HR according to light exposure

\begin{tabular}{|l|l|l||}
\hline \multicolumn{1}{|c|}{ Diastolic blood pressure } & \multicolumn{1}{c|}{ Systolic blood pressure } & \multicolumn{1}{c|}{ Heart beats } \\
\hline Control $v s$ Red $(\mathrm{p}=0.0029)$ & Control $v s$ Red $(\mathrm{p}=0.40)$ & Control $v s$ Red $(\mathrm{p}=0.01)$ \\
\hline \hline Control $v s$ Green $(\mathrm{p}=0.04)$ & Control $v s$ Green $(\mathrm{p}=0.86)$ & Control $v s$ Green $(\mathrm{p}=0.002)$ \\
\hline \hline Red $v s$ Green $(\mathrm{p}=0.13)$ & Red $v s$ Green $(\mathrm{p}=0.64)$ & Red vs Green $(\mathrm{p}=0.69)$ \\
\hline
\end{tabular}

* Statistical significant at $\mathrm{P}<0.05$

\section{Discussion}

Measurements were taken for blood pressure and heart rate. When compared with the control, the heart rate increased after exposure to red light and green light conditions. The effects were statistically significant. The results of this study show that red and green light had an effect on blood pressure and appeared to increase blood pressure, also the red light was more effective than green light. These results are in agreement with [12, 14].

Results showed that the diastolic blood pressure is more reactive to colored light in comparison to systolic blood pressure for both lights (red\& green) with provides a foundation for further research. When compared with the control condition, blood pressure (systolic and diastolic) increased after exposure to red-light. However, there was statistically significant effect of the test red light on diastolic blood-pressure change. The studies showed that in good health topics the average heart rate is rising when exposed to colored light [17]. The rise of heart rate may be mainly dependent on the light-caused rise activity of sympathetic of the autonomic nervous system [7].

\section{Conclusions}

The exposure to green and red light of cinema screen are altering autonomic nervous functions and affecting on cardiovascular system as expressed by increasing the blood pressure and heart rate. Diastolic blood pressure is more reactive to colored light than the systolic blood pressure.

\section{References}

[1]Bruno, C.; Jocelyne, B. and Guy C, The basic physiology and pathophysiology of melatonin "Sleep Medicine Reviews"(2005); pp11-24,2005.

[2]Sonnier, I. and Dow, M. The right hemisphere: seat of emotion colors. Education. (2001); 105,373-75.

[3] Marcelo F. Costa1. Color Vision Sensation and Perception. Front. Editorial:Psychol. ( 2016).

[4]Watchara, S. and Yodchanan,W. The Red and Blue Rooms affect to Brain Activity, Cardiovascular Activity, Emotion and Saliva Hormone in Women Conference: BMEICON.(2014).

[5]Matsuoka, T. psychology and color encyclopedia Mikasa-shobo, Tokyo.(2000); 102-104 [in Japanese].

[6]Partonen, T. and Lomqvist, J. Bright light improves vitality and alleviates distress in healthy people. J. Affect. Disord. (2000); 57:55-61.

[7]Axel, S. Karl, W. K. The Effect of Colored Illumination on Heart Rate Variability. in Forschende

Komplementärmedizin / Research in Complementary Medicine.(2006);13:167-73. 
The Influence of Cinema Screen Colors on The Heart Rate and Blood Pressure among Students in the

College of Fine Arts

[8]Huikuri, H.V.; Tkikallio, M.; Airaksinen, J.; Mitrani, R.; Castellanos, A. and Myerburg, R,J. Measurement of heart rate variability: a clinical tool or a research toy? J. Am. Coll. Cardiol. (1999); 34:187883.

[9]Pratibha, M.; Kamlesh, J.; Yogesh, K.; Tribhuwan, K.; Ramji, S. and Abhilasha, M. The effect of short-term exposure to red and blue light on the autonomic tone of the individuals with newly diagnosed essential hypertension. (2019);8: 14-21. [10]Pomeranz, B.; Macaulay ,R.J.B.; Caudill, M.A.; Kutz, I.; Adam, D.; Gordon, D.; Kilborn ,K.M.; Barger, A.C.; Shannon, D.C.; Cohen, R.J. and Benson, H. Assessment of autonomic function in humans by heart rate spec- tral analysis. Am J Physiol. (1985);248:151-53.

[11]P. K.; Bosner, M.S.; Kleiger, R.E. and Conger, B.M. Heart rate variability: a measure of cardiac auto- nomic tone. Am Heart J. (1994);127:1376-81.

[12]Engelbrecht, K. The impact of color on learning. Chicago. IL:Perkins\& Willa.(2003). [13]Kutchma, T. M. The Effects of Room Colour Stress Perception: Red versus Green Environments . Unpublished Liberal Arts Thesis of Minnesota State Univesity , Mankato.(2003).

[14]UKEssays. Effect of Colours on Blood Pressure [Internet]. November 2018. [Accessed 5 April 2019]; Available from: https://www.ukessays.com/essays/biology/eff ect-of-different-colours-on-blood-pressurebiology-essay.php?vref=1.
[15]Carmende, K.; Cathryn, T.; Séverine, S.; Xavier, B.; Antònia, V.; Archana, S.; Josep, M.; Jordi, A.; Mark, J.; Nieuwenhuijsen, J.; rdi,S. and Payam, D. Green and blue spaces and physical functioning in older adults: Longitudin alanalyses of the Whitehall Iii. Study (2018).

[16]Dadvand, P.; Nieuwenhuijsen, M.J. and Esnaola, M., et al. Green spaces and cognitive development in primary schoolchildren. Proc. Natl. Acad. Sci. U. S. A.(2015); 112:7942-73.

[17]Ruger, M. and Scheer, F.A. J. L. "Effects of circadian disruption on the cardiometabolic system," Reviews in Endocrine and Metabolic Disorders.(2009); 10: 245-60. 